Saul Wiesel MD MSc FRCPC, Michael J. Tessler MD FRCPC, L. Jane Easdown MD FRCPC

\title{
Postdural puncture headache: a randomized prospective comparison of the 24 gauge Sprotte and the 27 gauge Quincke needles in young patients
}

faction nor the acceptability of spinal anaesthesia for a future

This study was designed to compare the frequency of postdural puncture headaches (PDPH) using the 24 gauge Sprotte and the 27 gauge Quincke spinal needles in a population of patients less than $45 \mathrm{yr}$ of age undergoing spinal anaesthesia for nonobstetrical surgery. Patients were randomly assigned to receive spinal anaesthesia with either the 24 gauge Sprotte spinal needle $(n=46)$ or the 27 gauge Quincke spinal needle $(n=47)$. Patients were interviewed on either postoperative day one or two and on postoperative day three. A PDPH was defined as a headache involving the occipital or frontal areas that is made worse when assuming either the sitting or standing position. Ninety-three patients were included in the analysis of data. The overall incidence of PDPH was $14 \%$ (13 of 93), and no difference was found between the Sprotte (15.2\%) and Quincke (12.8\%) needles. The distribution of the PDPHs by severity was not different between the two groups. None of the 13 patients with PDPHs required an epidural blood patch for relief of symptoms. Both the Sprotte needle and the Quincke needles were judged as easy to use and both required the same number of attempts in order to locate cerebrospinal fluid (first attempt successful: $73.9 \%$ versus $66 \%$ ). Neither patient satis-

\section{Key words}

ANAESTHETIC TECHNIQUES: spinal; COMPLICATIONS: headache.

From the Departments of Anaesthesia, Sir Mortimer B. Davis-Jewish General Hospital and McGill University, Montreal, Canada.

Presented in part at the 49th Annual Meeting of the Canadian Anaesthetists' Society, June 1992, Toronto, Canada. Address correspondence to: Dr. Saul Wiesel, University of New Mexico School of Medicine, Dept. of Anesthesiology and Critical Care Medicine, Surge Building, Albuquerque, New Mexico, USA 87131-5216.

Accepted for publication 29th March, 1993. procedure was adversely affected by the occurrence of a PDPH. The results of this study suggest that the risk of PDPH after spinal anaesthesia in young patients is similar using either the 24 gauge Sprotte or the 27 gauge Quincke spinal needle.

Cette étude compare la fréquence de la céphalée postrachidienne (CPR) provoquée par l'aiguille $24 G$ Sprotte et Quincke $27 \mathrm{G}$ dans une population de patients de moins de 45 ans soumis à une anesthésie rachidienne pour chirurgie non obstétricale. Les patients sont répartis au hasard de façon à ce qu'on utilise soit l'aiguille rachidienne $24 G$ Sprotte ( $n=$ $46)$, soit l'aiguille rachidienne $27 G$ Quincke $(n=47)$. On interroge les patients le premier ou le deuxième jour après l'opération, et le troisième jour. Une CPR est définie comme une céphalée occipitale ou frontale aggravée par le position assise ou debout. Les données de 93 patients sont analysées. Lincidence totale des CPR est de $14 \%$ (13 de 93) et on ne trouve pas de différence entre l'aiguille Sprotte $(15,2 \%)$ et l'aiguille Quincke $(12,8 \%)$. La sévérité de la CPR n'est pas différente entre les deux groupes. Dans aucun des 13 cas de CPR, il n'est nécessaire de colmater avec du sang autologue. On juge les aiguilles Sprotte et Quincke faciles $\dot{a}$ utiliser et un nombre identique d'essais est requis pour ponctionner la dure-mère (succès au premier essai $73,9 \%$ vs 66\%). Le degré de satisfaction et d'acceptabilité n'ont pas été affectés par l'apparition de CPR. Les résultats de cette étude suggèrent que le risque de CPR après anesthésie rachidienne chez des jeunes patients est identique avec les deux auguilles rachidiennes utilisées, la Sprotte $24 G$ et la Quincke $27 G$.

Postdural puncture headache (PDPH) that can follow spinal anaesthesia may limit the application of this anaesthetic technique. It may lead to patient distress, prolonged hospitalization and require an epidural blood 
patch for resolution. In order to decrease the rate of PDPH, the smallest gauge Quincke needle available is used. The reported PDPH rates for the 27 gauge Quincke needle range from $1.5 \%$ to $3.7 \% \%^{1-4}$ and may even be as high as $10.45 \% .{ }^{5}$ While early studies using the noncutting Sprotte needle suggested a PDPH as low as $0.02 \%,{ }^{6}$ other studies in non-obstetrical patients do not appear to support these figures and suggest a PDPH rate of approximately $2.4 \%{ }^{7}$ and even as high as $8.2 \% .^{8}$ Furthermore, the higher cost of the Sprotte needle ${ }^{9}$ as well as the controversial issue of failed anaesthesia despite adequate return of cerebrospinal fluid ${ }^{10,11}$ may negate any advantages in reducing the rate of PDPH.

Younger patients appear to be at higher risk of PDPH than do older patients ${ }^{2,12-15}$ and would benefit greatly from a reduction in the rate of PDPH. Therefore, we compared the incidence of PDPH after use of the 24 gauge Sprotte and the 27 gauge Quincke needles for spinal anaesthesia in a population of young patients undergoing spinal anaesthesia for non-obstetrical surgery in a randomized, prospective manner.

\section{Methods}

Approval of the hospital Ethics and Research Committee and written informed consent were obtained from patients. As part of obtaining informed consent for spinal anaesthesia, patients were informed that there was a possibility that they would have a headache after the anaesthetic, but details concerning its character were not given. This prospective study involved 96 patients less than $45 \mathrm{yr}$ of age undergoing elective or emergency surgery. Obstetrical patients were excluded. Patients were randomized to receive spinal anaesthesia with either the 24 gauge Sprotte needle $(8.89 \mathrm{~cm}$; Pajunk, Germany) or the 27-gauge Quincke needle $(8.89 \mathrm{~cm}$; Becton Dickinson, Franklin Lake, New Jersey). The following data were recorded: patient age, sex, ASA classification, elective or emergency nature of the surgery, number of attempts at dural puncture, position during induction of spinal anaesthesia (sitting or lateral), type of anaesthetic agent (lidocaine or bupivacaine) and its baricity (hyperbaric or isobaric) and the addition of epinephrine or any narcotic (fentanyl or sufentanil) to the anaesthetic solution. The anaesthetist rated the use of the study needle as easy, moderately difficult or difficult. The Quincke needle was introduced with the bevel parallel to the sagittal plane. With either needle, the midline approach to lumbar puncture was used.

Patients were interviewed in person or by telephone (if discharged from the hospital) by an anaesthetist not involved with the case or by a research nurse. Both were blinded to the spinal needle used. Interviews took place on either postoperative days one or two and on post-
TABLE I Patient demographics

\begin{tabular}{lll}
\hline & Sprotte & Quincke \\
\hline$n$ & 46 & 47 \\
Mean age (SD) & $32.4(7.3)$ & $34.2(8.0)$ \\
Male/Female & $27 / 19$ & $23 / 24$ \\
Elective (\%) & $41(81.9)$ & $41(87.2)$ \\
ASA I,II,III & $41,5,0$ & $41,4,2$ \\
\hline
\end{tabular}

TABLE II Intraoperative variables

\begin{tabular}{lcc}
\hline & Sprotte & Quincke \\
\hline$n$ & 46 & 47 \\
Sitting position (\%) & $45(97.8)$ & $43(91.5)$ \\
Lidocaine (\%) & $37(80.4)$ & $37(78.7)$ \\
Bupivacaine (\%) & $9(19.6)$ & $10(21.3)$ \\
Hyperbaric (\%) & $41(89.1)$ & $39(83)$ \\
Isobaric (\%) & $5(10.9)$ & $8(17)$ \\
Epinephrine added (\%) & $1(2.2)$ & $2(4.3)$ \\
Narcotic added (\%) & $21(45.7)$ & $12(25.5)$ \\
Number of attempts: & & \\
- One (\%) & $34(73.9)$ & $31(66)$ \\
- Two (\%) & $11(23.9)$ & $14(29.8)$ \\
- Three or more (\%) & $1(2.2)$ & $2(4.3)$ \\
Difficulty (\% “Easy”) & 89.1 & 95.7 \\
\hline
\end{tabular}

operative day three. A headache was defined as a PDPH if it fulfilled the following two criteria: location in the occipital and/or frontal areas of the head with exacerbation of symptoms when sitting or standing. ${ }^{16}$ Severity of symptoms of PDPH were rated by the patients as mild, moderate or severe. Furthermore, on postoperative day three the patients were asked the following two questions: Were you satisfied with the anaesthetic you received? Would you wish to receive the same type of anaesthetic in the future for a similar surgical procedure?

Statistical analysis was performed using the Chi-square test with Yates' correction, with $P<0.05$ considered statistically significant.

\section{Results}

Initially, 96 patients were included in the study. None was excluded because of failure to obtain cerebrospinal fluid. Interviews could not be completed in three, leaving 93 for analysis (Sprotte group, $n=46$, Quincke group, $n=47$ ) with a $96.9 \%$ follow-up rate. Patient groups did not differ demographically (Table I). The two groups had similar anaesthetic drugs and positioning (Table II). Both spinal needles were judged to be similar in ease of use in terms of the number of attempts required to obtain CSF and the difficulty rating given by the anaesthetist (Table II). No spinal anaesthetic required conversion to a general anaesthetic. 
TABLE III Patient satisfaction/acceptance and spinal needle

\begin{tabular}{lll}
\hline & Sprotte & Quincke \\
\hline$n$ & 46 & 46 \\
$\begin{array}{l}\text { Satisfied with present anaesthetic: } \\
\text { - (\% "Yes") }\end{array}$ & $44(95.7)$ & $42(91.3)$ \\
$\begin{array}{l}\text { Would accept similar anaesthetic again: } \\
\text { - (\% "Yes") }\end{array}$ & $41(89.1)$ & $41(89.1)$ \\
\hline
\end{tabular}

TABLE IV Patient satisfaction/acceptance and PDPH

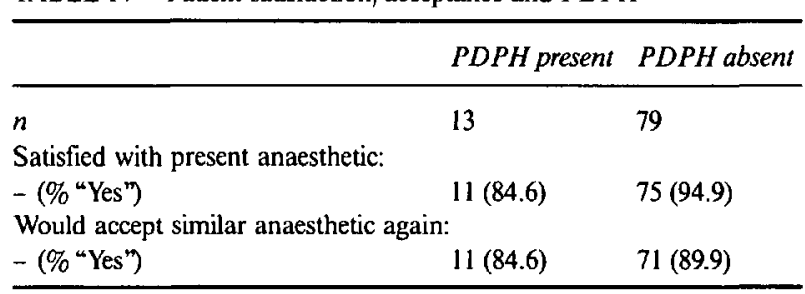

The overall incidence of PDPH was $14 \%$ (13 patients of 93). In the Sprotte group, seven patients had postdural puncture headache $(15.2 \%)$, compared with six patients in the Quincke group $(12.8 \%, \mathrm{NS})$. The severity of PDPHs was similar in each group: two patients described mild, one moderate and three severe symptoms. One patient in the Sprotte group could not rate the severity of the discomfort. None of the 13 patients with PDPH required an epidural blood patch to relieve symptoms.

Patient satisfaction with the spinal anaesthetic was equally high in both groups, as was the acceptance of a similar anaesthetic in the future (Table III). These did not decrease in those patients who developed a PDPH (Table IV). One patient could not decide whether he was satisfied with the anaesthetic or would accept a similar one in the future.

\section{Discussion}

The incidence of PDPH in the present study with the 27 gauge Quincke needle was $12.8 \%$ and is somewhat higher than the values, between $1.5 \%$ and $3.7 \%$, that others have reported. ${ }^{1-4}$ Previously, we reported a PDPH rate of $19.6 \%$ in patients less than $40 \mathrm{yr}$ of age using the 27 gauge Quincke needle. ${ }^{5}$ The reported PDPH rates vary considerably, for example, PDPH rates for the 25 gauge Quincke needle range from $7.8 \%$ to $37.2 \%,{ }^{13,15,17-23}$ and between $2 \%$ and $9.6 \%$ for the 26 gauge Quincke needle. ${ }^{2,15,19,24-27}$ While use of the 29 gauge Quincke needle has been reported to result in an incidence of PDPH between $0 \%$ and $2 \%$, the failure rate of between $1.2 \%$ and $8 \%$ may make its use impractical. 20,24,25,28,29

Variability in the reported frequency of PDPH may be a result of differences in patient populations, such as age and $\operatorname{sex}^{2,12}$ or intraoperative variables such as patient position, bevel orientation, ${ }^{14,30}$ type and baricity of anaesthetic agent, ${ }^{26}$ addition of opioid ${ }^{31}$ and intraoperative sedation. $^{7}$ The psychosomatic component of PDPH should be considered ${ }^{32,33}$ as well as the definition of PDPH used and the method of patient follow-up employed. The PDPH has been the subject of recent review articles. ${ }^{34-37}$

This study found a PDPH rate of $15.2 \%$ in young, non-obstetrical patients using the 24 gauge Sprotte needle. Studies with the Sprotte needle in obstetrical patients suggested a PDPH rate of between $0 \%$ and 5.6\%, $4,22,38-41$ and a lower incidence of PDPH than with the 25 gauge, $22,39,40$ the 26 gauge, ${ }^{40}$ but not the 27 gauge Quincke. ${ }^{4}$ The PDPH rate using the Sprotte needle in non-obstetrical anaesthesia has been reported to be between $2.4 \%{ }^{7}$ and $8.2 \%{ }^{8}$ and it offers no advantage, with regard to $\mathrm{PDPH}$, than either the $25^{7,8}$ or the 27 gauge Quincke needles.' These results are disappointing and are in contrast to the PDPH rate of $0.02 \%$ found by the needle's developer. ${ }^{6}$

Both needles were judged to have similar difficulty of placement by the three anaesthetists. All had sufficient experience using the Sprotte needle that the results of this study do not represent the early part of a learning curve.

We chose to limit the use of the Quincke needle with the bevel in the parallel orientation because this has been found to decrease the incidence of PDPH after spinal anaesthesia ${ }^{14,30}$ and dural puncture complicating epidural anaesthesia. ${ }^{42}$ Furthermore, in vitro studies support a decreased CSF leak with this orientation. ${ }^{43}$

Although half of the patients who reported a PDPH described their worst symptoms as severe, no blood patches were performed in the 13 patients who had a PDPH in the course of this study. Few data exist concerning the use of the 27 needle, ${ }^{4}$ but these support our observations that blood patches are rarely required because of resolution of symptoms within a reasonable period of time.

This study used a rigorous definition of a PDPH as a postdural headache, in the frontal or occipital areas, whose symptoms were aggravated by assuming the sitting position and alleviated by recumbency. ${ }^{16}$ Many of the headaches that occur after spinal anaesthesia may not be the result of dural puncture and should be differentiated from the PDPHs by the patient's history. ${ }^{13,25}$

The relatively high rate of PDPH that we describe for both spinal needles requires explanation. When the present study is compared with others using the 27 gauge Quincke needle, it appears that the patients in the present study were younger and followed up more closely than those reported by Flanagan et al.' (PDPH rate of 3.7\%). Kang $e t a l^{2}$ found a PDPH rate of only $1.8 \%$ in a sub- 
group of patients less than $40 \mathrm{yr}$ of age using anaesthetic techniques and a system of follow-up similar to our own. Similarly, looking at studies using the 24 gauge Sprotte needle in nonobstetric patients we find that our patients were younger than those reported by Tarkkila et al. ${ }^{7}$ (PDPH rate of $2.4 \%$ ) who relied on a questionnaire instead of interviews. Our PDPH rate is closer to that reported by Buttner et al. ${ }^{8}$ (PDPH rate $8.2 \%$ ) whose patients were older than ours but who relied on frequent interviews for a seven day postoperative period. We believe that our preoperative interview, which informs patients that a postoperative headache is a possible complication of spinal anaesthesia, combined with our method of interviewing patients may have uncovered a high incidence of transient PDPH symptoms.

Despite the incidence of PDPH, $84.6 \%$ of patients were satisfied with the conduct of their anaesthetic and would choose the same technique for a similar procedure. Other studies have found that the preference for spinal anaesthesia is dampened in those who experience a PDPH. ${ }^{2,15,18,21,27}$ Furthermore, the overall incidence of PDPH of $14 \%$ may still compare favourably with the more frequent occurrence of headache $(43 \%)$ following general anaesthesia. ${ }^{44}$

In conclusion, this study suggests that the risk of postdural puncture headache in young patients is similar after using either the 24 gauge Sprotte or the 27 gauge Quincke needles for spinal anaesthesia. The study does not support the use of the more expensive Sprotte needle in young patients at risk of PDPH.

\section{References}

1 Flanagan JF, Kumatta D, Black D. Comparison of 24 gauge Sprotte and 27 gauge Quincke needle on the incidence of post dural puncture headache. Anesth Analg 1991; $72:$ S75.

2 Kang SB, Goodnough DE, Lee $Y K$, et al. Comparison of 26- and 27-G needles for spinal anesthesia for ambulatory surgery patients. Anesthesiology 1992; 76: 734-8.

3 Hurley RJ, Hertwig LM, Lambert DH. Incidence of post dural puncture headache in the obstetrical patient: 25 gauge Whitacre vs 26 and 27 gauge Quincke tip needles. Reg Anesth 1992; 17: S33.

4 Majer DC, Quance D, Weeks SK. Headache after spinal anesthesia for Cesarean section: a comparion of the 27gauge Quincke and 24-gauge Sprotte needles. Anesth Analg 1992; 75: 377-80.

5 Coté S, Socci M, Wiesel S. Spinal anaesthesia with the 27 gauge needle. Can J Anaesth 1991; 38: A46.

6 Sprotte G, Schedel $R$, Pajunk $H$. Eine "atraumatische" Universalkanule fur einzeitige Regionalanaesthesien. Reg Anaesth 1987; 10: 104-8.

7 Tarkkila PJ, Heine H, Tervo R-R. Comparison of Sprotte and Quincke needles with respect to post dural puncture headache and backache. Reg Anesth 1992; 17: 283-7.

8 Bütner J, Wresch KP, Klose R. Bietet eine konisch geformte Kanulenspitze Vorteile bei der Spinalanaesthesie? Reg Anaesth 1990; 13: 124-8.

9 Dixon $C L$. The Sprotte, Whitacre, and Quincke spinal needles. Anesthesiology Review 1991; 18: 42-7.

10 Crone $L-A L$, Vogel $W$. Failed spinal anesthesia with the Sprotte needle (Letter). Anesthesiology 1991; 75: 717-8.

11 Bütner J, Wresch KP, Klose $R$. Fewer failed spinal anesthestics with the Sprotte needle (Letter). Anesthesiology 1992; 77: 393.

12 Vandam $L D$, Dripps $R D$. Long-term follow-up of patients who received 10,098 spinal anaesthetics. JAMA 1956; 161 : 586-91.

13 Flaatten H, Rodt S, Rosland J, Vamnes J. Postoperative. headache in young patients after spinal anaesthesia. Anaesthesia 1987; 42: 202-5.

14 Lybecker H, Møller JT, May O, Nielsen HK. Incidence and prediction of postdural puncture headache. A prospective study of 1021 spinal anesthetics. Anesth Analg 1990; 70: 389-94.

15 Sarma VJ, Boström U. Intrathecal anaesthesia for day-care surgery. A retrospective study of 160 cases using 25 - and 26-gauge spinal needles. Anaesthesia 1990; 45: 769-71.

16 Driessen A, Mauer W, Fricke M, Kossmann B, Schleinzer $W$. Prospective studies on the pathologic mechanism of post-spinal headache in a select group of patients. Anaesthetist 1980; 29: 38-41.

17 Crawford JS. Experience with spinal analgesia in a British obstetric unit. Br J Anaesth 1979; 51: 531-5.

18 Flaatten $H$, Raeder $J$. Spinal anaesthesia for outpatient surgery. Anaesthesia 1985; 40: 1108-11.

19 Barker $P$. Are obstetric spinal headaches avoidable? Anaesth Intensive Care 1990; 18: 553-4.

20 Guerts $J W$, Haanschoten $M C$, van Wijk RM, Kraak $H$, Besse TC. Post-dural puncture headache in young patients. A comparitive study between the use of $0.52 \mathrm{~mm}$ (25gauge) and $0.33 \mathrm{~mm}$ (29-gauge) spinal needles. Acta Anaesthesiol Scand 1990; 34: 350-3.

21 Rasmussen BS, Blom L, Hansen P, Mikkelsen SS. Postspinal headache in young and elderly patients. Two randomised, double-blind studies that compare 20 -and 25 gauge needles. Anaesthesia 1989; 44: 571-3.

22 Cesarini $M$, Torrielli $R$, Lahaye F, Mene JM, Cabiro $C$. Sprotte needle for intrathecal anaesthesia for Caesarean section: incidence of postdural puncture headache. Anaesthesia 1990; 45: 656-8.

23 Abboud TK, Zhu J, Reyes A, et al. Effect of subarachnoid morphine on the incidence of spinal headache. Reg Anesth 1992; 17: 34-6.

24 Dittmann $M, \operatorname{Renkl} F$. Spinal anesthesia with extremely fine needles (Letter). Anesthesiology 1989; 70: 1035-6. 
25 Flaatten H, Rodt SA, Vamnes J, Rosland J, Wisborg T, Koller ME. Postdural puncture headache; a comparison between 26- and 29-gauge needles in young patients. Anaesthesia 1989; 44: 147-9.

26 Naulty JS, Hertwig L, Hunt CO, Datta S, Ostheimer GW, Weiss JB. Influence of local anesthetic solution on postdural puncture headache. Anesthesiology 1990; 72: 450-4.

27 Quaynor $H$, Corbey $M$, Berg $P$. Spinal anaesthesia in daycare surgery with a 26-gauge needle. Br J Anaesth 1990; 65: 766-9.

28 Dahl JB, Schultz P, Anker-Møller E, Christensen EF, Staunstrup $H G$, Carlsson P. Spinal anaesthesia in young patients using a 29 -gauge needle: technical considerations and an evaluation of postoperative complaints compared with general anaesthesia. Br J Anaesth 1990; 64: 178-82.

29 Lynch J, Arhelger S, Krings-Ernst I. Post-dural puncture headache in young orthopaedic in-patients: comparison of a $0.33 \mathrm{~mm}$ (29-gauge) Quincke-type with a $0.7 \mathrm{~mm}$ (22gauge) Whitacre spinal needle in 200 patients. Acta Anaesthesiol Scand 1992; 36: 58-61.

30 Mihic DN. Postspinal headache and relationship of needle bevel to longitudinal dural fibers. Reg Anesth 1985; 10: 76-81.

31 Johnson MD, Hertwig L, Vehring PH, Datta $S$. Intrathecal fentanyl may reduce the incidence of spinal headache. Anesthesiology 1989; 71 : A911.

32 Kaplan $G$. The psychogenic etiology of headache post lumbar puncture. Psychosom Med 1967; 29: 376-9.

33 Daniels $A M$, Sallie $R$. Headache, lumbar puncture, and expectation (Letter). Lancet 1981; 1: 1003.

34 Gielen $M$. Post dural puncture headache (PDPH): a review. Reg Anesth 1989; 14: 101-6.

35 Lambert $D H$. Complications of spinal anesthesia. Int Anesthesiol Clin 1989; 27: 51-5.

36 Gerard KW, Fagraeus $L$. Postspinal headache. Seminars in Anesthesia 1990; 9: 69-74.

37 Weeks $S K$. Spinal headache - prevention and treatment. Can J Anaesth 1990; 37: S53-8.

38 Cambell DC, Douglas MJ, Pavy TJC, Flanagan ML. McMorland GH. Comparison of 25G Whitacre vs $24 \mathrm{G}$ Sprotte needles for Caesarean section. Can J Anaesth 1992; 39: A46.

39 Devcic A, Sprung J, Maitra-D'Cruze A, Haddox JD. Post-dural puncture headache in an obstetric population: comparison of 24-ga Sprotte and 25-ga Quincke needles. Reg Anesth 1992; 17: S69.

40 Ross BK, Chadwick HS, Mancuso JJ, Benedetti C. Sprotte needle for obstetric anesthesia: decreased incidence of post dural puncture headache. Reg Anesth 1992; 17 29-33.

41 Schneider $M$, Schuhmacher P, Kaufmann M. Incidence of postdural puncture headache (PDPH) in young pregnant and nonpregnant women after spinal anesthesia with a $24 \mathrm{G}$ Sprotte needle. Reg Anesth 1992; 17 : S93.

42 Norris $M C$, Leighton $B L$, DeSimone $C A$. Needle bevel direction and headache after inadvertant dural puncture. Anesthesiology 1989; 70: 729-31.

43 Ready LB, Cuplin S, Haschke RH, Nessly M. Spinal needle determinants of rate of transdermal fluid leak. Anesth Analg 1989; 69: 457-60.

44 Fennelly M, Galletly DC, Purdie GI. Is caffeine withdrawal the mechanism of postoperative headache? Anesth Analg 1991; 72: 449-53. 